\title{
The Study on Suspension Velocity of Tobacco Fragment in Exhaust Hood of Tunnel-type Damping Machines
}

\author{
Yongxiang Zhao ${ }^{1, ~ a, ~ G u a n g b o ~ Z h a n g ~}{ }^{1, b}$, Weixue Cao ${ }^{2, ~ a, ~ X u e-y i ~ Y o u ~}{ }^{2, b^{*}}$ \\ ${ }^{1}$ Tianjin Cigarette Factory, Shanghai Tobacco Group Co. Ltd, Tianjin, China 300163 \\ ${ }^{2}$ School of Environmental Science and Engineering, Tianjin University, Tianjin, China 300072

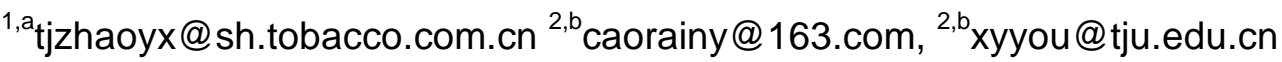

Keywords: Tunnel-type damping machines; fragment tobacco; suspension velocity; simulation Abstract. The suspension velocity of tobacco fragment is theoretically and numerically studied in tunnel-type damping machines. The movement of fragment tobacco is described by Euler-Lagrange theory. The proposed model is solved numerically, and the relationship of the shape, size and flow field of fragment tobacco with the suspension velocity is obtained. Based on the numerical results, the theoretical suspension velocity of fragment tobacco is modified. The study provides guidance for related equipment design and optimization.

\section{Introduction}

The suspending technique is widely used in food, chemical, petroleum, mining, cement, tobacco and others fields for high efficiency, less pollution, easy to maintain and suitable for long distance transportation. In the tobacco fields, it is mainly used to transport and cleaning. In the 1990s, fluidized bed technology and road transport purify technology were developed. Tobacco suspending technique is a typical fluid-particle two-phase flow. Yang [1] discussed many modeling systems. Seibert and Buens [2] used statistical mechanics approach to simulate a variety of systems. Lin [3] analyzed the impact of the initial velocity on the particle flow characteristics. Zhou et al [4] used the finite element method to simulate tobacco pneumatic conveying. Gan et al [5] studied experimentally the suspension velocity of the tobacco material in the vertical pipe.

The tunnel-type damping machine is major equipment in tobacco industry. It is used to make tobacco fragment heated and humidified before tobacco drying process. The working principle is that the driving vibration trough is droved by the eccentric drive to produce low amplitude high frequency vibrations of tunnel to convey the material achieved. Both the inlet and outlet of pipe system are equipped with an exhaust pipe system to makes the steam tunnel spillover steam drain away [6,7].

\section{Problems of exhaust hood}

The structure of exhaust hood is shown in Fig. 1. After the heat exchange between the silk and the steam, the rest of the steam is driven by air flow produced by the exhaust blower in the exhaust hood exit. The dust is carried by the material and the very fine cut tobacco is discharged to the odor treatment system. The air flow inside of the unreasonable box makes the production process malfunction. When the wind velocity becomes large, a number of particulate together with the cut tobacco and the water vapor are transported to the exit of the system with over standard tobacco particle content. This makes the subsequent odor treatment system unmorally. Meanwhile, as the wind velocity small, the dust particles can not be effectively discharged. In short, the control of the internal air flow improves greatly on the quality of products. Fluent is used to study the flow filed of the damping machine. The reasonable discharge speed is determined to ensure the tobacco concentration of outlet not exceed $50 \mathrm{mg} / \mathrm{m}^{3}$. 


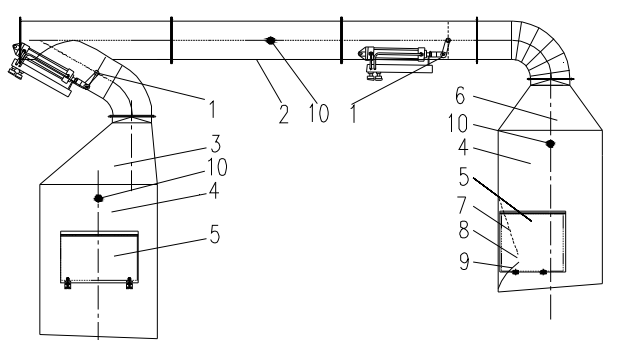

1-damper 2-duct 3-spout 4-box 5-observation door 6-inlet7-slide cigarette end plate

8-introduction openings 9 -air deflector 10 -wind speed measuring point

Fig. 1. The structure diagram of the tunnel-type damping machine

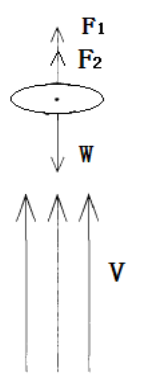

a
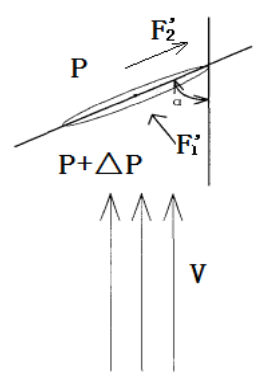

b

Figure 2. Cut tobacco particles in the stream of force analysis

\section{Theoretical of particle suspension}

The suspension of cut tobacco particles is mainly affected by buoyancy, gravity and flow around. When balanced, the gas speed is known as the freely suspended particle velocity. It is equal to the free settling velocity [8]. Assuming the cut tobacco particles is spherical, the particles in suspension satisfies the force balance equation:

$$
\frac{1}{6} \pi d_{p}^{3} \rho_{g} g+C_{D} \frac{1}{2} \rho_{g} v_{f}^{2} \frac{\pi}{4} d_{p}^{2}=\frac{1}{6} \pi d_{p}^{3} \rho_{d} g
$$

Where, the first and the second terms of left-hand of the equation are buoyancy and resistance and the term of right-hand side is gravity. $d_{p}$ is the particle diameter. $V_{f}$ is particle suspended speed, $\rho_{p}$ and $\rho_{g}$ are the density of particles and gas respectively. $g$ is gravitational acceleration, $C_{D}$ is drag coefficient. The free suspended of particle speed is:

$$
V_{f}=\sqrt{\frac{4 g d_{p}\left(\rho_{p}-\rho_{g}\right)}{3 C_{D} \rho_{g}}}
$$

In general, the air density is much lower than that of tobacco particle, Eq .2 is simplified to:

$$
V_{f}=\sqrt{\frac{4 g \rho_{p} d_{p}}{3 \rho_{g} C_{D}}} \approx 3.62 \sqrt{\frac{\rho_{p} d_{p}}{\rho_{g} C_{D}}}
$$

The drag coefficient $C_{D}=f(\mathrm{Re})$ is refer to manual[9].

The cut tobacco particles are not spheres and they are thin rod-like, as shown in Fig. 2. The gravity force of thin rod-like tobacco on the particles is:

$$
W=K S_{0}\left(\frac{V_{f}^{2} \rho_{g}}{2}\right)[c \sin \alpha+(2+c) \sigma \cos \alpha]
$$

Where, $W=\rho_{p} g S_{0} \delta, \delta$ is the average thickness of tobacco leaf, $S_{0}$ is the whole leaves exhibition area, $K$ is expansion coefficient and $\mathrm{K}=1$ is for fully extended. $c$ is pressure coefficient, $\alpha$ is the leaves attitude angle, $\sigma$ is friction of blade and air. The cut tobacco particle suspension velocity is:

$$
V_{f}=K_{1}[\sin (\alpha+\beta)]^{-\frac{1}{2}}, \quad K_{1}=\sqrt{\frac{2 g \rho_{p} \delta}{K \rho_{g}}\left[c^{2}+(2+c)^{2} \sigma^{2}\right]^{\frac{1}{2}}} ; \beta=\arctan \frac{(2+c) \sigma}{c} .
$$

The occurrence probability of attitude angle of cut tobacco is equal, the average suspension speed can be considered as the average velocity of the attitude angle between $0 \sim \pi$ as: 
$\overline{V_{f}}=\left(\frac{1}{\pi}\right) \int_{0}^{\pi} V_{f} d \alpha$

\section{Numerical Simulation}

The control equations of air flow in the tunnel-type damping machine are adopted as those in reference [10]. For the trajectory of cut tobacco, the motion is calculated by Lagrangian method:

$$
\frac{d u_{p i}}{d t}=\frac{18 \mu}{\rho_{p} d_{p}^{2}} \frac{C_{D} \operatorname{Re}}{24}\left(u_{g i}-u_{p i}\right)+g_{x}\left(\rho_{p}-\rho_{g}\right) / \rho_{p}+F_{x}
$$

Where $u_{g i}$ is the fluid phase velocity, ${ }^{u_{p i}}$ is the particle velocity, $\mu$ is the viscosity of the fluid, $d_{p}$ is the particle diameter, $C_{D}$ is the drag coefficient refers to the Fluent manual:

\section{Results and discussion}

The density of tobacco particles is affected by the ambient relative humidity, the accumulation volume, apparent volume and true volume. When tobacco humidified or heating by different saturated steams, the moisture content varies in range of $19 \%$ to $24 \%$, and the relative humidity is in $75 \%$ to $79 \%$. The cut tobacco density is about $0.741 \mathrm{~g} / \mathrm{cm}^{3}$ measured in Tianjin Cigarette Factory.

The shape coefficients of tobacco particle are shown in Table 1. Theoretical analysis shows that the area size of the cut tobacco has a great impact on the suspension velocity. The relationship between the suspension velocity and the shape factor is shown in Fig. 3.

Table 1 Typical dimensions of leaf shape coefficient

\begin{tabular}{|c|c|c|c|}
\hline shape & $\Longrightarrow=$ & $\Rightarrow$ & $\oplus$ \\
\hline size & 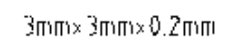 & 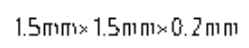 & וחוח0.2×וח וח0.5× וחוח0.5 \\
\hline shape factor & 0.35 & 0.49 & 0.95 \\
\hline
\end{tabular}

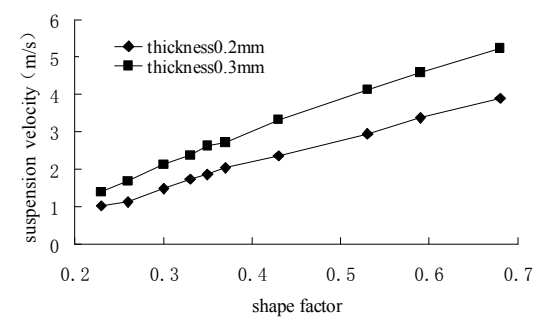

Figure 3. The suspension velocity with respect to shape factor of cut tobacco

Figure 4 The suspension velocity with respect to shape factor $(0.2 \mathrm{~mm})$

Fig. 3 shows the suspension velocity increases with the shape factor. When the cut tobacco is close to spherical, the suspension velocity is increased. When the thickness increases, the suspension velocity is also increased. The suspensions velocity is nearly proportional to shape factor. The suspension velocity with respect to shape factor is shown in Fig. 4.

The inlet boundary condition is the atmospheric pressure and the outlet boundary condition is the pressure outlet. According to the measurement, the air volume flow rate is $4527 \mathrm{~m}^{3} / \mathrm{h}$ and the opening of the valve is $70 \%$. Fig. 5 shows the exhaust hood internal velocity field. The wind speed is between $1 \sim 2 \mathrm{~m} / \mathrm{s}$ and the velocity near the value increase to the average wind velocity between $4 \sim 6 \mathrm{~m} / \mathrm{s}$. 

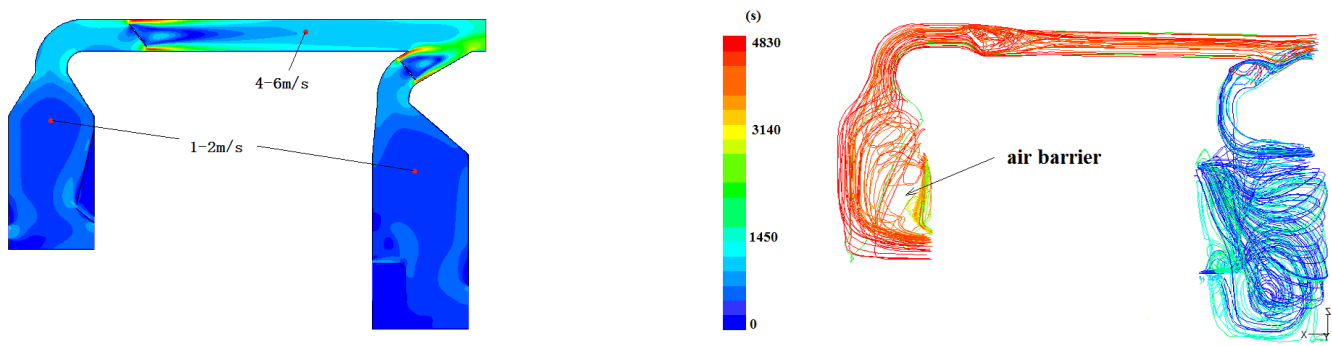

Figure 5. The velocity distribution and streamline of the tunnel-type damping machine

Fig. 5 shows the velocity distribution and streamline. The result shows the suspension velocity becomes large when the shape factor increases. This is the same as that of theoretical analysis. The simulation value is about $12 \%$ higher than that of theoretical value. The main reasons may be contributed to the following assumption in the theory: (1) the tobacco movement is in infinite space; (2) the impact of shape factor and attitude angle of suspension particle is not fully considered; (3) it fails to consider the effect of collision of particles. According to the numerical results, the modified theoretical suspension velocity is as follows:

$$
V_{f N}=1.12 \overline{V_{f}}
$$

\section{Conclusions}

The theoretical and numerical approaches on the suspension velocity of cut tobacco are studied in the exhaust hood of tunnel-type damping machine. The cut tobacco model is established by Euler-Lagrange theory. The relationship of suspension velocity of cut tobacco particle with its shape, size and flow field is obtained. Based on the numerical results, the modified theoretical suspension velocity of tobacco particle is found. The outcome provides guidance for the design and optimization of similar equipments.

\section{Acknowledgement}

The research was supported by Tianjin cigarette factory of Shanghai tobacco Group Ltd.

\section{References}

[1] Yang W C. Handbook of fluidization and fluid-particle systems. Boca Raton, Florida: CRC Press, Inc., 2003.

[2] Seibert K D, Burns M A. Simulation of fluidized beds and other fluid-particle systems using statistical mechanics. American Institute of Chemical Engineers, 1996, 42(3): 660-670.

[3] Lin Jiang, Research on gas-solid two-phase flowing characteristics of accelerating zone in pneumatic conveying system. Journal of Zhejiang University (Engineering Science), 38(7): 893-898. In Chinese.

[4] Zhou Hui, Yang Xiangjie, Zou Wei, Xu Lin. Analysis on Pneumatic Conveying in Cigarette Factory by the Finite Element Method. Machine tool and hydraulics, 2007, 35(1): 217-220. In Chinese.

[5] Gan Fangjian, Pan Xiaoyang, Hu Kaiwen. On transported velocity of the raw material of tobacco. Journal of Hefei University of Technology (natural science edition), 1999, 22(2):130-133. In Chinese.

[6] Zhang Guangbo. Wash water recycling Develop in a Tunnel-type Pre-conditioner. China Tobacco 2010 Annual Conference Proceedings, 2010.100-103. In Chinese.

[7] The State Tobacco Monopoly Bureau, Cigarette process specifications, Central Literature Publishing House, 2003.04. In Chinese. 
[8] Wu Lei, Hu Tianqun, Du Guofeng. Experiment and numerical simulation for the pneumatic characteristics of cut tobaccos in a wind tunnel. Chinese Journal of Hydrodynamics, 2011, 26(1): 123-128. In Chinese.

[9] John D. Anderson. Development and Application of Computational Fluid Dynamics, Beijing: Mechanical Industry Press, 2011.

[10] Haider A, Levenspie O, Drag coefficient and terminal velocity of spherical and nonspherical particles. Powder Technology, 1989, 58(11): 63-70. 